\title{
PARVOVIRUS B19 ASSOCIATED HAEMOPHAGOCYTIC LYMPHOHISTIOCYTISIS IN HEREDITARY SPHEROCYTOSIS PATIENT: A CASE REPORT
}

\author{
Cheong $C S^{1}$, Gan $G^{1}$, Chen $T M^{1}$, Lim $C C^{1}$, Nadarajan $V S^{2}$, Bee $P C^{1}$ \\ 1 Department of Medicine, Faculty of Medicine, University of Malaya, Kuala Lumpur \\ 2 Department of Pathology, Faculty of Medicine, University of Malaya, Kuala Lumpur
}

\section{Correspondence:}

Dr. Cheong Chin Sum, Professor Dr. Gan Gin Gin, Associate Professor Dr. Bee Ping Chong

Department of Medicine

Faculty of Medicine

University of Malaya

50603 Kuala Lumpur

Email:chinsum@gmail.com,gangg@ummc.edu.my,pcbee@um.edu.my

\begin{abstract}
Haemophagocytic lymphohistiocytosis (HLH) is a clinico-pathologic entity caused by increased proliferation and activation of benign macrophages with haemophagocytosis throughout the reticulo-endothelial system. Virus-associated HLH is a well-recognised entity. Although majority of parvovirus B19 associated HLH does not require any specific treatment and carries good prognosis, outcome of children is worse than adults. We report here a case of $\mathrm{HLH}$ associated with acute parvovirus B19 infection in a young healthy patient with underlying hereditary spherocytosis, with bone marrow findings typical of parvovirus infection. Although this patient had spontaneous recovery of cell counts, he succumbed due to complication from prolonged ventilation. Unexpectedly, his immunoglobulin levels were inappropriately normal despite on-going ventilator associated pneumonia, which reflects inadequate humoral immune response towards infection.
\end{abstract}

Keywords: Hemophagocytic lymphohistiocytosis; hereditary spherocytosis, Parvovirus.

\section{Introduction}

Haemophagocytic lymphohistiocytosis $(\mathrm{HLH})$ is a clinicopathologic entity caused by a defect in inflammatory signals that results in increased proliferation and activation of benign macrophages with haemophagocytosis throughout the reticulo-endothelial system (1). The disease is seen in all ages and has no predilection for race and sex (2).

$\mathrm{HLH}$ is a reactive process resulting from an uncontrolled immune response triggered by different stimuli with an underlying inherited or acquired inability to regulate this trigger. Persistent stimulation of lymphocytes and histiocytes results in hypercytokinemia, leading to characteristic symptoms of HLH (3).

Characteristic symptoms of HLH are prolonged fever, hepatosplenomegaly and cytopenias. Other features of $\mathrm{HLH}$ is the presence of haemophagocytosis typically seen in involved organs such as liver (4) as well as bone marrow (5). However, haemophagocytosis is initially absent in majority of patients. In patients with pre-existing chronic haemolysis, parvovirus induced transient aplastic crisis may lead to severe anaemia (6). The typical changes in the bone marrow of patients with HLH secondary to parvovirus B19 infection are haemophagocytosis of mature and immature hematopoietic cells, in addition to myeloid and erythroid hypoplasia, as well as variable megakaryocyte hyperplasia (7). Intranuclear parvovirus B19 inclusions in red cell precursors have rarely been described in patients with transient aplastic crisis. Other laboratory values that suggest HLH include high ferritin, raised triglycerides, transamininitis, increased bilirubin and SCD25 (alpha-chain of the soluble interleukin-2 receptor) levels, and decreased fibrinogen. Although all these symptoms are characteristic, none is specific (2).

$\mathrm{HLH}$ can be categorised into genetic and acquired form, based on aetiology. The genetic form of HLH includes familial $\mathrm{HLH}$, and those associated with other primary immunodeficiency syndromes. Familial HLH is an autosomal recessive disease caused by several mutations in the NK/Tcell cytotoxic pathway. Immune-deficiency syndromes known to be associated with HLH include Chediak-Higashi 
syndrome, Griscelli syndrome type 2, Hermansky-Pudlak syndrome type 2 and $\mathrm{X}$-linked proliferative syndrome (2).

Acquired HLH is often subcategorised into infectionassociated $\mathrm{HLH}$, malignancy-associated $\mathrm{HLH}$ and $\mathrm{HLH}$ in association with autoimmune disease (5). It has also been reported in patients receiving immunosuppressive therapy after transplant (2). The true incidence of acquired $\mathrm{HLH}$ is unknown and may be under-recognised in adult critical care units (8).

HLH associated with infection was initially described in immune-suppressed patients (9). Various infectious organisms have been associated with $\mathrm{HLH}$. Viral infections associated with the syndrome include Epstein-Barr virus (EBV), cytomegalovirus (CMV), hepatitis viruses, human herpesvirus 8 (HHV8), influenza virus, parvovirus B19, and enterovirus (10). HLH may be the first manifestation of a human immunodeficiency virus (HIV) infection (11). However, EBV is the most common triggering agent.

Parvovirus B19 infection typically cause erythema infectiosum in children (12), acute polyarthritis in adults (13), and transient aplastic crisis in patients with chronic haemolytic anaemia such as sickle cell anaemia (14) or hereditary spherocytosis (15). Parvovirus B19 associated with HLH is less common than that of EBV. In previous case reports, parvovirus B19 associated HLH was more prevalent among adults patients (16). More than half of the patients have an underlying disease, the most common being hereditary spherocytosis (16). Other underlying conditions that were present in previous case reports include sickle cell anaemia and iron deficiency anaemia. Most of these patients had spontaneous recovery without specific therapy, while some of them were treated with corticosteroids or intravenous immunoglobulin (16-23). This condition has showed a benign clinical course in more than $80 \%$ of the cases. The low mortality suggests that parvovirus B19 associated HLH carries a better prognosis compared to other viral associated HLH (10).

HLH is a difficult diagnosis to make as it can be easily confused with any infective process and not all of the above clinical signs are present. It is the magnitude of clinical symptoms and laboratory abnormalities and especially their progression, which suggest the diagnosis when these patients do not respond appropriately to the treatment (2).

We report here a case of HLH associated with acute parvovirus B19 infection in a previously young and healthy patient with underlying hereditary spherocytosis who succumbed to complication related to $\mathrm{HLH}$.

\section{Case Presentation}

A 15-year-old boy with underlying hereditary spherocytosis (HS), presented with 3-day-history of fever and chills. It was associated with nausea, vomiting and abdominal pain, as well as diarrhea. He also complained of lethargy, myalgia and loss of appetite. There was no history of headache or symptoms of respiratory tract infection. There was no significant travel history. The patient was conscious but disoriented upon arrival at the emergency department. He was febrile at $39.2^{\circ} \mathrm{C}$. He was also tachycardic. Abdominal examination revealed mild splenomegaly. There was neck stiffness and macular rash at the posterior aspect of his neck. Physical examination of other systems was unremarkable. Blood investigations showed that he was mildly anaemic, with a raised white cell count, and normal platelet level. The lactate dehydrogenase and bilirubin were elevated at $2030 \mathrm{U} / \mathrm{L}$ and $36 \mathrm{umol} / \mathrm{L}$ respectively, consistent with haemolysis likely secondary to underlying hereditary spherocytosis. Chest X-ray revealed mild cardiomegaly while CT scan of brain was normal. An empirical diagnosis of meningo-encephalitis was entertained and he was treated with intravenous ceftriaxone 2 grams twice daily and intravenous acyclovir 500 milligrams three times a day.

However, his condition rapidly deteriorated over the next 12 hours, with low blood pressure requiring inotropic support and mechanical intubation for respiratory failure. This was further complicated with disseminated intravascular coagulopathy the following day with persistent spiking fever. Antibiotic was upgraded to intravenous meropenem 500 milligrams four times a day. In view of the dropping haemoglobin level, he had two units of packed cells transfusion. On day 3 of admission, the maculopapular rash had spread from his neck to trunk and abdomen. There was now hepatomegaly. The full blood counts had worsened with hemoglobin $7.3 \mathrm{~g} / \mathrm{dL}$, white cell count $2.3 \times 10^{9} / \mathrm{L}$ and platelet $18 \times 10^{9} / \mathrm{L}$. Serum ferritin was elevated at $103,700 \mu \mathrm{g} / \mathrm{L}$, while his fasting triglyceride was mildly raised at $1.8 \mathrm{mmol} / \mathrm{L}$. The HIV screening test was negative. A preliminary diagnosis of $\mathrm{HLH}$ was made in view of the results. Bone marrow examination was performed on day 4 of admission. The bone marrow was hypercellular but there was a lack of erythroid precursors together with giant proerythroblasts; several histiocytes were seen scattered among the haematopoietic cells with a number of them showing haemophagocytosis. There were also several large cells, which show large round or ovoid nuclei with peripheral chromatin condensation and intranuclear inclusion resembling 'lantern cells' seen in the marrow (Figure $1 \mathrm{~A}$ and $1 \mathrm{~B}$ ). In view of this, parvovirus infection was suspected and this was later confirmed with a raised parvovirus B19 IgM.

Although his blood counts recovered spontaneously on day 11 of admission, he unfortunately developed multidrug-resistant Acinetobacter baumanii ventilatorassociated pneumonia and acute respiratory distress syndrome (ARDS) (Figure 2). Serum immunoglobulin levels were inappropriately normal (IgG $1130 \mathrm{mg} / \mathrm{dL}$, IgA $301 \mathrm{mg} / \mathrm{dL}$, IgM $80 \mathrm{mg} / \mathrm{dL}$ ) despite on-going infection. His condition deteriorated despite treatment with intravenous colistin 150 milligrams twice a day and succumbed to the complication on day 22 of admission. 

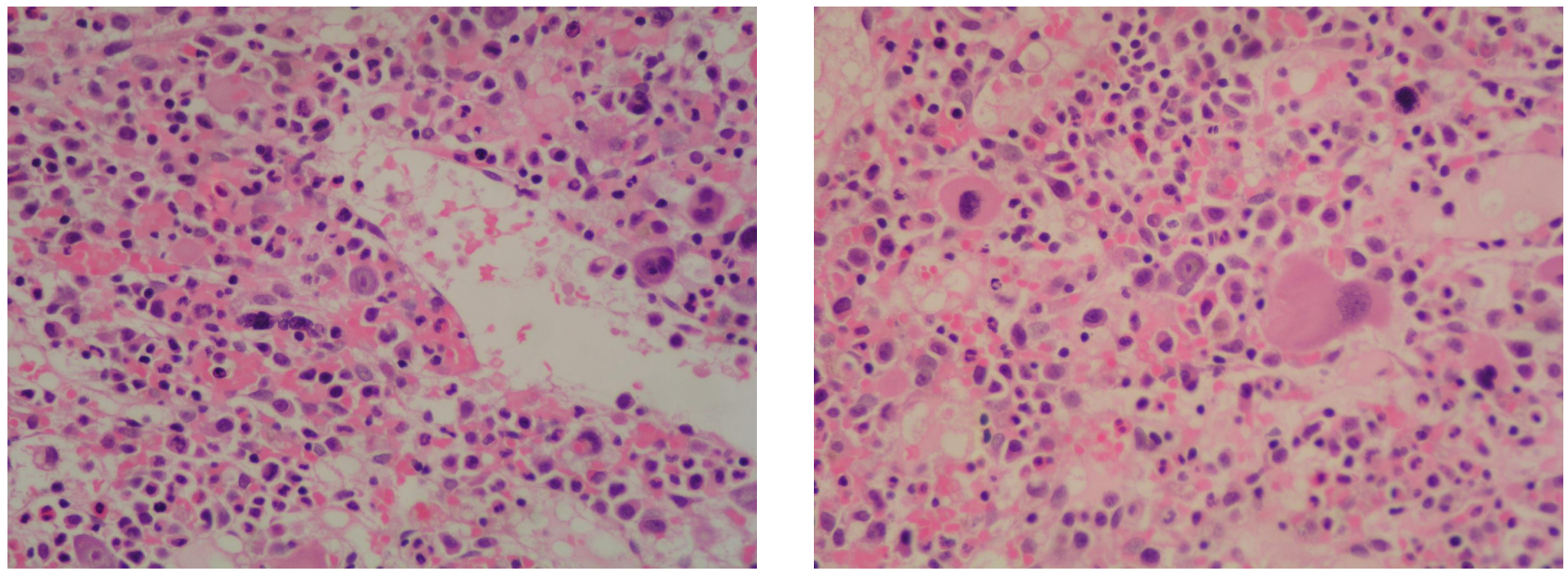

Figure 1A and 1B: Bone marrow trephine at 20x magnification. Erythroblast with intranuclear eosinophilic inclusions, suggestive of parvovirus B19 infection.

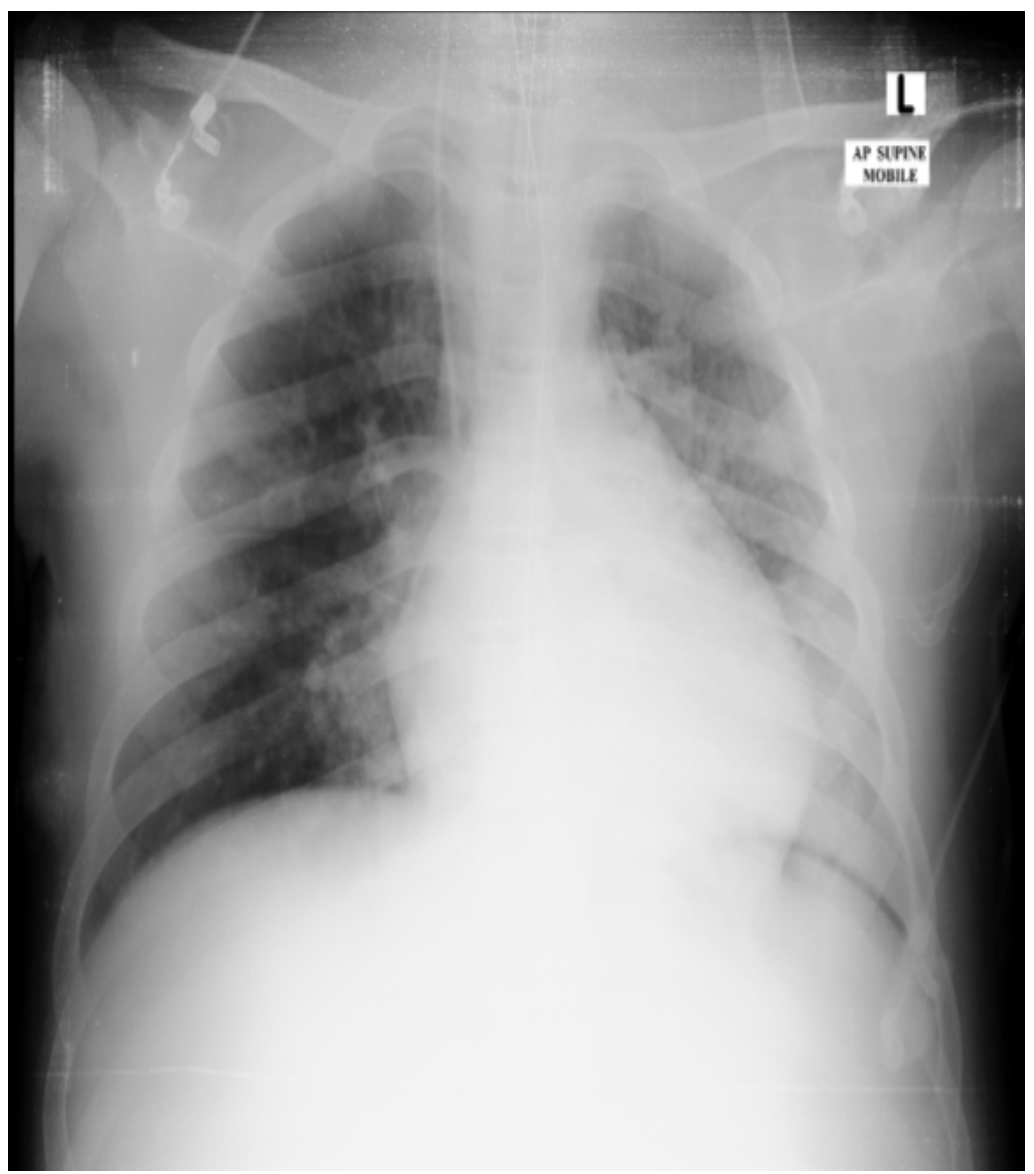

Figure 2: Chest X-ray showing acute respiratory distress syndrome picture.

\section{Discussion}

$\mathrm{HLH}$ is a rare and complex syndrome that can present with pancytopaenia. The diagnosis of this syndrome requires the presence of 5 or more of the following: fever, splenomegaly, cytopaenia affecting at least 2 lineages in the peripheral blood, hypertriglyceridemia or hypofibrinogenemia, low or absent natural killer cell activity, a serum ferritin level higher than $500 \mathrm{ug} / \mathrm{L}$, soluble CD25 higher than 2,400 U/ml, or hemophagocytosis as demonstrated in bone marrow, spleen, or lymph node (24). This patient has fulfilled six out of eight criteria, except for measurement of natural killer cell activity and soluble CD25 levels, which were not available in our institution. However, it was adequate for the diagnosis of HLH. The aetiology of HLH was confirmed with positive IgM parvovirus B19 serology, as well as the 
typical bone marrow findings of erythroid hypoplasia and giant proerythroblast, together with large cells with intranuclear inclusions resembling 'lantern cells' seen in acute parvovirus B19 infection.

There are 32 cases of parvovirus B19 associated HLH reported so far in the literature, including our case (1623). Sixteen of the patients were adults while another sixteen patients, were children. Most of the patients with parvovirus B19 associated HLH patients in other case reports recovered spontaneously without receiving any specific treatment, suggesting better outcome compared with other virus-associated HLH (10). There is no specific antiviral drug against parvovirus B19 and the infection does not normally need treatment in immune-competent host (25). However, patients in more recent case reports have received intravenous immunoglobulin as part of the treatment. There was only one death $(6.3 \%)$ reported among adult patients, compared to five mortalities (31.3\%) among children. The low mortality among adult patients, despite the fact that majority of them not receiving any specific therapy, suggests better outcome in this cohort, compared to children who have higher mortality despite treatment.

In this previously health and young boy, the development of $\mathrm{HLH}$ secondary to parvovirus B19 infection has significantly affected his immune system, rendering ineffective NK and $\mathrm{T}$ cell activation to kill parvovirus infected cells and antigen presenting cells. The fact that this patient did poorer compared to other parvovirus B19 infected patients could be due to his inability to mount an immune response against infection as suggested by an inappropriately normal serum immunoglobulin levels for someone with overwhelming infection.

In previous study looking at characteristic immune abnormalities in HLH, most patients with HLH have normal quantitative serum immunoglobulin levels with no consistent pattern of immunoglobulin deficiency (26). While the humoral immunity is essentially intact, cellular function is abnormal in most. The authors concluded that HLH have consistent and significant abnormalities in cytotoxic immune function (26). This boy in our case has demonstrated signs of recovery based on laboratory parameters. However, secondary infection from prolonged intensive care unit stay and ventilation has led to his death, predisposed by immunocompromised state from $\mathrm{HLH}$.

The HLH-2004 protocol recommends an 8-week induction therapy with corticosteriods, etoposide, and cyclosporin A upfront, for the treatment of $\mathrm{HLH}$ (24). In cases of infectionassociated $\mathrm{HLH}$, malignancy $\mathrm{HLH}$ or macrophage activation syndrome in idiopathic juvenile arthropathy, immediate treatment of the underlying disease is indicated (2). Among all virus associated $\mathrm{HLH}$, EBV carries the worst prognosis (27). The addition of etoposide in the therapy, especially if initiated within the first 4 weeks from diagnosis, improves survival (28).
Early intervention and more aggressive therapy as recommended by HLH 2004 protocol may have been indicated in this patient, rather than supportive care to shorten the course of disease. Complications of prolonged ventilation may then be avoidable. This may alter the outcome of this patient.

\section{Conclusion}

HLH remains a rare condition that can lead to fatal complications without early recognition. Although parvovirus B19 infection associated HLH carries good prognosis without specific treatment in previous reports, there was still significant mortality among children. Early intervention and more aggressive treatment is indicated in patients who have evidence of immunocompromised state to shorten the course of disease and to improve outcome.

\section{References}

1. Imashuku S. Differential diagnosis of hemophagocytic syndrome: underlying disorders and selection of the most effective treatment. Int J Hematol. 1997; 66(2):135-151.

2. Janka GE. Familial and acquired hemophagocytic lymphohistiocytosis. Annu Rev Med 2012; 63:233246.

3. Janka GE, Lehmberg K. Hemophagocytic lymphohistiocytosis: pathogenesis and treatment. Hematology Am Soc Hematol Educ Program 2013; 2013:605-611.

4. Chen JH, Fleming MD, Pinkus GS, et al. Pathology of the liver in familial hemophagocytic lymphohistiocytosis. Am J Surg Pathol. 2010; 34(6):852-867.

5. Rosado FG, Kim AS. Hemophagocytic lymphohistiocytosis: an update on diagnosis and pathogenesis. Am J Clin Pathol. 2013;139(6):713-727.

6. Saarinen UM, Chorba TL, Tattersall $P$, et al. Human parvovirus B19-induced epidemic acute red cell aplasia in patients with hereditary hemolytic anemia. Blood. 1986; 67(5):1411-1417.

7. Crook TW, Rogers BB, McFarland RD, et al. Unusual bone marrow manifestations of parvovirus B19 infection in immunocompromised patients. Hum Pathol. 2000; 31(2):161-168.

8. Buyse S, Teixeira L, Galicier L, et al. Critical care management of patients with hemophagocytic lymphohistiocytosis. Intensive Care Med. 2010; 36(10):1695-1702

9. Risdall RJ, McKenna RW, Nesbit ME, et al. Virusassociated hemophagocytic syndrome: a benign histiocytic proliferation distinct from malignant histiocytosis. Cancer. 1979; 44(3):993-1002.

10. Rouphael NG, Talati NJ, Vaughan C, Cunningham K, Moreira R, Gould C. Infections associated with haemophagocytic syndrome. Lancet Infect Dis. 2007; 7(12):814-822.

11. Sun HY, Chen MY, Fang CT, Hsieh SM, Hung CC, Chang SC. Hemophagocytic lymphohistiocytosis: an unusual 
initial presentation of acute HIV infection. J Acquir Immune Defic Syndr. 2004; 37(4):1539-1540.

12. Anderson MJ, Higgins PG, Davis LR, et al. Experimental parvoviral infection in humans. J Infect Dis. 1985; 152(2):257-265.

13. Reid DM, Reid TM, Brown T, Rennie JA, Eastmond CJ. Human parvovirus-associated arthritis: a clinical and laboratory description. Lancet. 1985; 1(8426):422425.

14. Pattison JR, Jones SE, Hodgson J, et al. Parvovirus infections and hypoplastic crisis in sickle-cell anaemia. Lancet. 1981; 1(8221):664-665.

15. Kelleher JF, Luban NL, Mortimer PP, Kamimura T. Human serum "parvovirus": a specific cause of aplastic crisis in children with hereditary spherocytosis. J Pediatr. 1983; 102(5):720-722.

16. Larroche C, Scieux C, Honderlick P, Piette AM, Morinet F, Bletry $\mathrm{O}$. Spontaneous resolution of hemophagocytic syndrome associated with acute parvovirus B19 infection and concomitant EpsteinBarr virus reactivation in an otherwise healthy adult. Eur J Clin Microbiol Infect Dis. 2002; 21(10):739-742.

17. Yilmaz S, Oren H, Demircioglu F, Firinci F, Korkmaz A, Irken G. Parvovirus B19: a cause for aplastic crisis and hemophagocytic lymphohistiocytosis. Pediatr Blood Cancer. 2006; 47(6):861.

18. Mayama M, Yoshihara M, Kokabu T, Oguchi H. Hemophagocytic lymphohistiocytosis associated with a parvovirus B19 infection during pregnancy. Obstet Gynecol. 2014; 124(2 Pt 2 Suppl 1):438-441.

19. Kaya Z, Ozturk G, Gursel T, Bozdayi G. Spontaneous resolution of hemophagocytic syndrome and disseminated intravascular coagulation associated with parvovirus b19 infection in a previously healthy child. Jpn J Infect Dis. 2005; 58(3):149-151.

20. Matsubara K, Uchida Y, Wada T, et al. Parvovirus B19-associated hemophagocytic lymphohistiocytosis in a child with precursor B-cell acute lymphoblastic leukemia under maintenance chemotherapy. J Pediatr Hematol Oncol. 2011; 33(7):565-569.

21. Ardalan MR, Shoja MM, Tubbs RS, Esmaili $H$, Keyvani H. Postrenal transplant hemophagocytic lymphohistiocytosis and thrombotic microangiopathy associated with parvovirus b19 infection. Am J Transplant. 2008; 8(6):1340-1344.

22. Kishore J, Kishore D. Fatal missed case of hemophagocytic lymphohistiocytosis co-infected with parvovirus B19 and Epstein-Barr virus in an infant: test hyperferritinaemia early. Indian J Med Microbiol. 2014; 32(2):181-183.

23. Dutta U, Mittal S, Ratho RK, Das A. Acute liver failure and severe hemophagocytosis secondary to parvovirus B19 infection. Indian J Gastroenterol. 2005; 24(3):118-119.

24. Henter Jl, Horne A, Arico M, et al. HLH-2004: Diagnostic and therapeutic guidelines for hemophagocytic lymphohistiocytosis. Pediatr Blood Cancer. 2007; 48(2):124-131.

25. Broliden K, Tolfvenstam T, Norbeck O. Clinical aspects of parvovirus B19 infection. J Intern Med. 2006; 260(4):285-304.

26. Egeler RM, Shapiro R, Loechelt B, Filipovich A. Characteristic immune abnormalities in hemophagocytic lymphohistiocytosis. J Pediatr Hematol Oncol. 1996; 18(4):340-345.

27. Janka G, Imashuku S, Elinder G, Schneider M, Henter JI. Infection- and malignancy-associated hemophagocytic syndromes. Secondary hemophagocytic lymphohistiocytosis. Hematol Oncol Clin North Am. 1998; 12(2):435-444.

28. Imashuku S, Kuriyama $\mathrm{K}$, Teramura $\mathrm{T}$, et al. Requirement for etoposide in the treatment of Epstein-Barr virus-associated hemophagocytic lymphohistiocytosis. J Clin Oncol. 2001; 19(10):26652673. 